\title{
Erratum to: Vision-Based Kidnap Recovery with SLAM for Home Cleaning Robots
}

\author{
Seongsoo Lee $\cdot$ Sukhan Lee $\cdot$ Seungmin Baek
}

Published online: 3 May 2014

(C) Springer Science+Business Media Dordrecht 2014

Erratum to: J Intell Robot Syst (2012) 67:7-24

DOI 10.1007/s10846-011-9647-4

In the above paper, equation (1) was incorrectly published and is correctly written as follows:

$X^{*}=\underset{X=\left\{x_{1}, \ldots, x_{k}\right\}}{\operatorname{argmin}} \sum_{i, j}\left(z_{i, j}-x_{j} \ominus x_{i}\right)^{T} W_{i, j}\left(z_{i, j}-x_{j} \ominus x_{i}\right)$,

The online version of the original article can be found at http://dx.doi.org/10.1007/s10846-011-9647-4.

S. Lee $(\bowtie) \cdot$ S. Lee $(\bowtie)$

School of Information and Communication Engineering and Department of Interaction Science, Sungkyunkwan University, Suwon, South Korea

e-mail: seongsu.lee@lge.com

e-mail: 1sh@ece.skku.ac.kr

\section{S. Lee $\cdot$ S. Baek}

Future IT Laboratory, LG Electronics Inc.,

Seoul, South Korea

e-mail: seungmin2.baek@1ge.com 